\title{
Isolation of Clostridium difficile from patients and the environment of hospital wards
}

\author{
HELEN MALAMOU-LADAS, S O'FARRELL, JQ NASH, SOAD TABAQCHALI
}

From the Department of Medical Microbiology, St Bartholomew's Hospital, West Smithfield, London ECIA $7 B E$

SUMMARY Rectal swabs from 122 patients and 497 environmental swabs from several wards were examined for the presence of Clostridium difficile in order to assess the role of the environment ini the spread of this organism. Clostridium difficile was isolated from 6/27 (22.2\%) oncology patients and from $8 / 163(4.9 \%)$ environmental specimens obtained from the oncology unit. Items found $\infty_{\infty}^{\circ}$ positive for $C$ difficile were those subjected to faecal contamination such as commode chairs, bedo pans, dust pans, discard bins, the sluice and a disposable bed pan machine.

Fourteen of $51(27.4 \%)$ asymptomatic neonates yielded mostly toxigenic $C$ difficile in their stools during their first week of life. Five of $156(3 \cdot 2 \%)$ specimens taken from inanimate objects in the environment of the neonatal units were positive for $C$ difficile. The organism was also isolated from the hands of a nurse.

Similar antibiogram patterns were demonstrated in the strains obtained from the patients and their environment indicating the possible occurrence of cross infection.

These results indicate that environmental contamination is important in the spread of $C$ difficile in hospitalised patients and the implementation of isolation procedures may limit that spread.

The epidemiology of Clostridium difficile diarrhoeal disease has not yet been clarified. Although $C$ difficile is the most important cause of antibiotic-associated colitis (AAC), ${ }^{12}$ it is also isolated from up to $3 \%$ of healthy adults ${ }^{3}$ and $40 \%$ of asymptomatic neonates. ${ }^{4}$ It is still uncertain therefore, whether AAC results from intestinal overgrowth of $C$ difficile in asymptomatic carriers, ${ }^{5}$ or whether the organism is newly acquired from the environment. ${ }^{0-9}$

Investigations of hospital outbreaks of $\mathrm{AAC},{ }^{6-9}$ studies in hamsters ${ }^{1011}$ and the isolation of $C$ difficile from inanimate objects and from contacts of patients with AAC,,$^{1213}$ suggest that the environment may act as a source of infection for hospitalised patients.

Because of the above uncertainty, we conducted this study to investigate the frequency of isolation of $C$ difficile from patients and the environment of several wards in the hospital to determine whether the environment acts as a reservoir of $C$ difficile and whether the implementation of isolation precautions limits the spread of the organisms. Antibiograms were used as a possible marker for $C$ difficile strains.

Accepted for publication 21 July 1982

\section{Material and methods}

The patients and the environment of (i) Oncology (ii) Urology, (iii) Intensive Care Unit (ICU), (iv) Maternity and (v) Special Care Baby Unit (SCBU were investigated for the presence of $C$ difficile.

Three surveys were carried out in the oncolog ward over a two-month period. The first survey was conducted after repeated isolation of $C$ difficile from a patient with acute myeloid leukaemia whळ developed severe diarrhoea three days after starting chemotherapy and antibiotic treatment for gut. decontamination (framycetin, nyastatin and colistiny) and gentamicin and erythromycin for septicaemia. The ward is partitioned to accommodate 13 oncolog patients and 13 general medical patients, all using the same bathroom and sluice room. Thirty-two sample? from 27 oncology patients, 13 samples from 13 general medical patients and 163 environmenta samples were obtained during the three surveys.

Two surveys were conducted in the urology ward which had 16 patients. The initial survey was starte $\&$ after the isolation of $C$ difficile from a patient wite carcinoma of the bladder who was on chemotherap and developed severe diarrhoea. He had received G 
ten-day course of cotrimoxazole three weeks earlier. This patient was immediately removed to a single room and isolation procedures implemented. Rectal swabs from all the patients and environmental samples, were tested during the two surveys. Specimens from 31 patients, 130 environmental samples and fingerprints from four nurses were obtained. The intensive care unit had three patients, none of whom had diarrhoea, 48 environmental samples were taken.

The maternity unit, has two main wards with individual nursing rooms, where mothers and their babies are hospitalised for one week. Premature babies are transferred to SCBU. The newborns and the environment were examined on three occasions during a four-month period. Samples were obtained from 51 neonates, 156 from the environment and fingerprints from 24 nursing staff.

Rectal swabs were obtained from a total of 122 patients and 497 swabs (Exogen Ltd, Glasgow) from the environment of the main wards (floors, bedding, utensils, cosmetics, cupboards, etc), the bathrooms and the sluice rooms of the five units and were inoculated immediately on sampling on the wards onto prereduced selective media (CCFA), ${ }^{14}$ placed in GasPak jars (BBL) and then incubated anaerobically at $37^{\circ} \mathrm{C}$ for $48-72 \mathrm{~h}$. Specimens obtained from the hands of 52 nursing staff by pressing their fingers onto CCFA plates were also immediately placed in GasPak jars and incubated as above. In addition, 13 air samples (320 l/sample) were obtained from the different wards by using the Biotest RCS centrifugal air sampler (Biotest-Folex Ltd) with CCFA strips, and 49 milk samples taken from the feeding bottles at the end of the feed were inoculated onto CCFA plates. All plates and strips were incubated in an anaerobic chamber $\left(85 \% \mathrm{~N}_{2}, 10 \% \mathrm{H}_{2}, 5 \% \mathrm{CO}_{2}\right)$ at $37^{\circ} \mathrm{C}$ and examined daily for one week.

Clostridium difficile strains were identified by their colonial and cellular morphology, the fluorescence under untraviolet light $^{14}$ and the characteristic pattern of volatile fatty acids using gas liquid chromatography. ${ }^{15}$

\section{CYTOTOXICITY ASSAY}

The supernatants of the $C$ difficile strains, incubated into Robertson's cooked meat broth for five days, were examined for cytotoxin production, using $\mathrm{Hep}_{2}$ cells. $^{1}$

The toxin titre was expressed as the highest dilution, which produced cytopathic effect on the monolayer neutralised by $C$ sordellii antitoxin (Ex 5128-Wellcome). ${ }^{1}$

\section{ANTIBIOTIC SUSCEPTIBILITY}

The minimum inhibitory concentration of $C$ difficile strains to a variety of antimicrobial agents were determined by using the Sensititre plate assay method. ${ }^{16}$ One to two strains per faecal specimen were tested.

\section{Results}

Table 1 shows the results of the three surveys in the oncology ward. During the first survey carried out three weeks after the initial isolation of $C$ difficile from the index patient, $C$ difficile was isolated from an asymptomatic general medical patient only and not from the remainder of the patients or from the index patient who was on vancomycin therapy. Of the 43 environmental specimens taken at that time only three were positive for $C$ difficile. These were obtained from a commode wheelchair, a clean bed pan, and a dustpan and brush in the sluice room.

On the second survey, three weeks later, 5/10 oncology patients had diarrhoea and their stools yielded $C$ difficile; three of the five had been culturenegative during the first survey. One was the index patient who had a recurrence of his diarrhoea after the termination of vancomycin therapy and the other two had been transferred recently to beds on either side of him. Of the 63 environmental samples taken from the vicinity of the index patient and from the main ward, the bathroom and the sluice room, four were positive. These were from items in the sluice room (a commode chair, a dustpan and brush, a discard bin and the sluice). On the third survey six weeks later, none of the medical but two of the oncology patients yielded $C$ difficile and the only one positive environmental specimen was obtained from a disposable bed pan machine in the sluice room (Table 1). Hence, eight of the $163(4.9 \%)$ of environmental samples were positive for $C$ difficile, and all isolates were recovered from items in the sluice room. All specimens obtained from the hands of the nursing staff and from the air samples in the oncology ward were negative. All $C$ difficile strains isolated from the

Table 1 Isolation of C difficile from patients and the environment of the oncology unit during three surveys

\begin{tabular}{llll}
\hline & \multicolumn{3}{l}{ Survey for C difficile (no positive/no examined) } \\
\cline { 2 - 4 } & $I$ & 2 & 3 \\
\hline Patients & $1 / 11(9 \cdot 0 \%)$ & $5 / 10(50 \%)$ & $2 / 24^{*}(8 \cdot 3 \%)$ \\
tAntibiogram & $\mathrm{A}$ & $2 \mathrm{~A}, 1 \mathrm{~B}, 2 \mathrm{C}$ & $2 \mathrm{~A}$ \\
Environment & $3 / 47(6 \cdot 3 \%)$ & $4 / 63(6 \cdot 3 \%)$ & $1 / 53(1 \cdot 8 \%)$ \\
tAntibiogram & $2 \mathrm{~A}, 1 \mathrm{~B}$ & $3 \mathrm{~A}, 1 \mathrm{~B}$ & $1 \mathrm{~B}$ \\
\hline
\end{tabular}

* Includes 13 general medical patients.

† See Table 5 . 
above patients and from their environment were toxigenic with titres ranging from $1 / 2$ to $1 / 2000$ (Table 2 ). In the first survey in the urology ward only the index patient had $C$ difficile in his stools and all other specimens from the patients and the environment were negative. Similarly all specimens obtained during the second survey were also negative for $C$ difficile (Table 3 ).

In the ICU unit, only one specimen obtained from a clean bed pan yielded $C$ difficile (Table 3 ). At that time, none of the three patients nursed in the unit had diarrhoea.

The overall results of the survey in the neonatal units are shown in Table 3. Fourteen of the 51 $(27.4 \%)$ newborns had $C$ difficile in their stools and all were asymptomatic. One of them was delivered by caesarean section and the others by normal vaginal delivery. The carriage rate was higher in the premature neonates in the SCBU (54\%) than in the normal neonates in the maternity ward $(20 \%)$.

Of the 156 environmental samples taken during the three surveys from the neonatal units $3 \cdot 2 \%$ were positive for $C$ difficile. The four positive environmental samples in the maternity unit were obtained from a crib in the main ward, a discard bin, a linen discard bag and a hand basin in the nursing rooms (Table 4). All the milk samples were negative for $C$ difficile.

In the SCBU, $C$ difficile was isolated from the hands of a nurse and from a discard bin for used nappies.

Ten of 14 strains isolated from the newborns and 3

Table 2 Toxin production by the $C$ difficile strains isolated from patients and the environment

\begin{tabular}{|c|c|c|c|c|}
\hline \multirow[b]{3}{*}{ Toxin titre } & \multicolumn{4}{|c|}{ No of strains in: } \\
\hline & \multicolumn{2}{|c|}{ Neonatal units } & \multicolumn{2}{|c|}{ Oncology unit } \\
\hline & Neonates & Environment & Patients & Environment \\
\hline $\begin{array}{l}<1 / 2 \\
1 / 2 \\
1 / 20 \\
1 / 200 \\
1 / 2000\end{array}$ & $\begin{array}{l}7 \\
2 \\
1\end{array}$ & $\begin{array}{l}1 \\
3\end{array}$ & $\begin{array}{l}3 \\
2 \\
2 \\
1\end{array}$ & $\begin{array}{l}1 \\
2 \\
5\end{array}$ \\
\hline
\end{tabular}

of 6 environmental strains were toxigenic with titre ranging from $1 / 2$ to $1 / 200$ (Table 2 ).

Antibiotic susceptibility testing of $C$ difficile strains showed three distinct sensitivity patterns A, B, and $C_{8}^{+}$ (Table 5). Patterns A, B and C were found in the oncology ward whereas the remainder of the strain belonged to pattern $\mathrm{A}$.

Table 3 Isolation of $C$ difficile from patients and the environment in several units

\begin{tabular}{|c|c|c|c|}
\hline \multirow[t]{2}{*}{ Units } & \multicolumn{3}{|c|}{ Number positive/number examined (\%) } \\
\hline & Patients & Environment & Staff finger prin \\
\hline Oncology & $\begin{array}{l}{ }^{*} 6 / 27(22 \cdot 2) \\
+1 / 13(7 \cdot 6)\end{array}$ & $8 / 163(4 \cdot 9)$ & $0 / 30$ \\
\hline Urology & $1 / 31(3 \cdot 2)$ & $0 / 130(0)$ & $0 / 4$ \\
\hline ICU & ND & $1 / 48(2)$ & ND \\
\hline $\begin{array}{l}\text { Maternity } \\
\text { (normal neonates) } \\
\text { Special baby care } \\
\text { (premature }\end{array}$ & $8 / 40(20)$ & $4 / 83(4 \cdot 8)$ & $0 / 14$ \\
\hline $\begin{array}{l}\text { neonates) } \\
\text { Totals }\end{array}$ & $\begin{array}{l}6 / 11(54 \cdot 5) \\
22 / 122(18)\end{array}$ & $\begin{array}{l}1 / 73(1 \cdot 3) \\
14 / 497(2 \cdot 8)\end{array}$ & $\begin{array}{l}1 / 10(10) \\
1 / 58(1 \cdot 7)\end{array}$ \\
\hline
\end{tabular}

ND: not done

* Leukaemia patients.

$\dagger$ Medical patients.

Table 4 Distribution of $C$ difficile in the environment of the newborn units

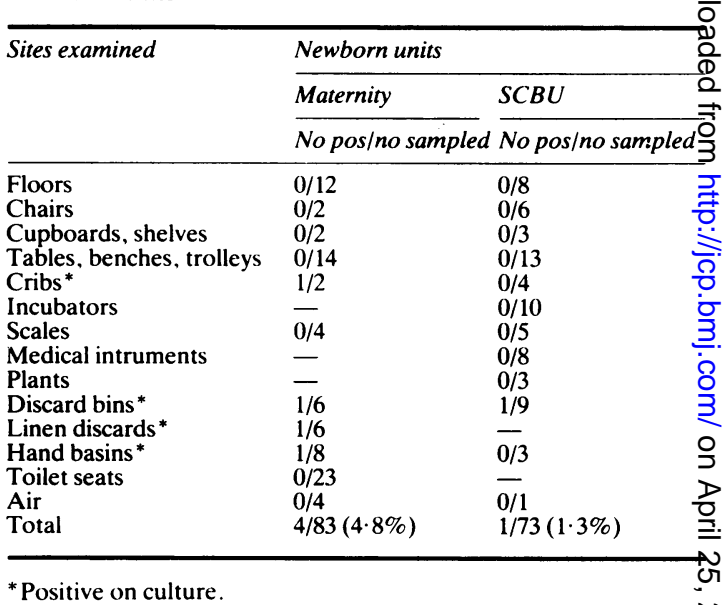

*Positive on culture.

Table 5 Antibiotic susceptibility patterns of $C$ difficile isolated from patients and their environment

\begin{tabular}{|c|c|c|c|c|c|c|c|c|}
\hline \multirow{2}{*}{$\begin{array}{l}\text { Sensitivity } \\
\text { pattern }\end{array}$} & \multicolumn{8}{|c|}{ Antibiotics (mg/l) } \\
\hline & Penicillin & Clindamycin & Metronidazole & $\begin{array}{l}\text { Chloran- } \\
\text { phenicol }\end{array}$ & Cefoxitin & Erythromycin & Carbenicillin & Cephalexin \\
\hline $\begin{array}{l}\text { A } \\
\text { B } \\
\text { C }\end{array}$ & $\begin{array}{l}1-2 \\
8 \\
4\end{array}$ & $\begin{array}{l}0 \cdot 25-0 \cdot 5 \\
0 \cdot 51-1 \\
32-64\end{array}$ & $\begin{array}{l}1-2 \\
4-8 \\
1-2\end{array}$ & $\begin{array}{l}2-4 \\
4 \\
4-8\end{array}$ & $\begin{aligned} & 64-128 \\
&> 128 \\
& 128\end{aligned}$ & $\begin{aligned} & 0 \cdot 25-0.5 \\
& 0 \cdot 5-1 \\
> & 64\end{aligned}$ & $\begin{array}{c}4-8 \\
16-32 \\
16-32\end{array}$ & $\begin{aligned} & 64-128 \\
> & 128 \\
> & 128\end{aligned}$ \\
\hline
\end{tabular}




\section{Discussion}

The possible acquisition of $C$ difficile from the environment has been suggested by reports of hospital outbreaks of AAC. ${ }^{6-9}$ The results of this study provide some evidence that environmental contamination with $C$ difficile may act as a source of infection in susceptible patients.

The spread of $C$ difficile in the oncology ward may have originated from the index patient who excreted $C$ difficile continuously for four weeks with no special isolation procedures being undertaken. His initial therapy with metronidazole failed to eradicate the organism and it was after vancomycin was started that his stools became negative. However, the patient had a symptomatic relapse when the drug was discontinued. This relapse may have been caused by either reinfection with $C$ difficile from an environmental source or persistence of spores in the gastrointestinal tract. ${ }^{17}$

The further isolation of $C$ difficile from $5 / 10$ oncology patients in the second survey suggests a possible transmission of $C$ difficile from patient to patient either directly or via the contaminated items in the unit. Of the environmental samples from the oncology ward, $4.9 \%$ were positive for $C$ difficile. These were from items subjected to faecal contamination in the sluice room, as shown in previous observations. ${ }^{13} 18$

Despite the limited number of antibiotics tested, the results showed three different sensitivity patterns in the $C$ difficile strains isolated from the patients and the environment of the oncology ward. Furthermore one patient who during the second survey, had a type C strain (clindamycin- and erythromycin-resistant), had a type (A) strain six weeks later which suggests either the loss of resistance or more likely, the new acquisition of a type A strain from the environment.

The rates of positive cultures from the environment of the oncology ward were higher $(6.3 \%)$ in the first two surveys when the patients had diarrhoea than from the third survey $(1 \cdot 8 \%)$ or from the other units $(1 \cdot 3-4 \cdot 8 \%)$ where the patients were asymptomatic. Similar findings have been reported by Kim et al. ${ }^{13}$

In contrast, the immediate isolation of the patient in the urology ward and the implementation of strict isolation procedures appear to have been effective in limiting the spread of the organisms. However, it is also possible that the patient population of the urology ward is not susceptible to colonisation unlike the oncology patients. The high incidence of $C$ difficile in the gastrointestinal tract of the oncology patients found in this study $(22.2 \%)$ and reported by others $(40 \%),{ }^{13}$ suggests that these patients form a highly susceptible group. This may be related to the intensive chemotherapy and antibiotic usage which alter the normal intestinal flora and may eradicate the enteric organisms with inhibitory activity against $C$ difficile ${ }^{1920}$-ie the colonisation resistance factors. Antibiotics, however, do not appear to play a role in the high rates of colonisation in neonates with $C$ difficile. Fourteen of $51(27 \cdot 4 \%)$ asymptomatic neonates who had never received antibiotics harboured $C$ difficile, during their first week of life. The isolation rate was particularly high in the premature babies $(54.4 \%)$ compared to the full-term neonates $(20 \%)$. These findings differ from those reported by Viscidi $e t a^{22}$ who found the incidence was comparable in the two groups. The reason for this high prevalence ${ }^{242122}$ and the rare incidence of AAC in neonates ${ }^{23}$ is still not clear, nor is it clear how neonates acquire this organism. Our data suggest that neonates were colonised from the environment probably via the hands of nursing staff, particularly since all the strains isolated from the environment and neonates had the same antibiogram (type A). It is unlikely that mother-baby acquisition occurs during vaginal delivery as was suggested by Hafiz and his colleagues, ${ }^{24}$ because one of our newborns with a positive culture was delivered by caesarean section and two of six caesarean section babies examined daily for the presence of $C$ difficile in their stools were found to be positive on the third and fifth day after their birth (unpublished data).

It appears therefore that $C$ difficile, which is spread in the environment of the hospital, can be acquired by susceptible patients, especially those who lack resistance to colonisation by $C$ difficile. So far, a typing scheme is not available to distinguish the different strains of $C$ difficile and to trace their spread in the hospital environment but extensive antibiograms may be helpful in the meantime. Decontamination of items subject to faecal contamination along with careful hand washing to prevent the spread of the organism are recommended. Furthermore, enteric isolation precautions should be introduced for patients who are shedding $C$ difficile, similar to those instituted successfully in our urology unit.

We wish to thank Dr A Lister and Mr Gordon Bourne for allowing us to study their patients and the nursing staff of these units for their co-operation. We should also like to thank Miss Lorraine Hall for typing the manuscript.

Dr Helen Malamou-Ladas was supported by a Post Doctoral Research Fellowship from the "Alexander S Onassis" Benefit Foundation. 


\section{References}

' Bartlett JG, Moon N, Chang TW, Taylor N, Onderdonk AB. Role of Clostridium difficile in antibiotic-associated pseudomembranous colitis. Gastroenterology 1978;75:778-82.

${ }^{2}$ Boriello SP, Larson HE. Antibiotic and pseudomembranous colitis. J Antimicrob Chemother 1981;7 suppl A:53-62.

${ }^{3}$ Phillips KD, Rogers PA. Rapid detection and presumptive identification of Clostridium difficile by p-cresol production on a selective medium. J Clin Pathol 1981;34:642-4.

${ }^{+}$Hall IC, O'Toole E. Intestinal flora in newborn infants with description of a new pathogenic anaerobe Bacillus difficilis. Am $J$ Dis Child 1935;49:390-402.

${ }^{5}$ Keighley MRB, Burdon DW, Mogg GAG, George RH. Alexander-Williams $J$, Thompson $\mathrm{H}$. Pseudomembranous colitis. (Letter) Lancet 1979; ;:559-60.

- Tedesco FJ, Barton RW, Alpers DH. Clindamycin-associated colitis: a prospective study. Ann Intern Med 1974;81:429-33.

${ }^{7}$ Kabins SA, Spira TJ. Outbreak of clindamycin-associated colitis (letter) Ann Intern Med 1975;83:830-1.

${ }^{8}$ Kappas A, Shingawa N, Arabi Y et al. Diagnosis of pseudomembranous colitis. Br Med J 1978; i:675-8.

${ }^{9}$ Milligan DW, Kelly JK. Pseudomembranous colitis in a leukaemia unit: a report of five fatal cases. J Clin Pathol 1979;32:1237-43.

${ }^{10}$ Larsen HE, Price AB, Borriello SP. Epidemiology of experimental enterocolitis due to Clostridium difficile. J Infect Dis 1980;142:408-13.

"Toshaiwal R, Silva J, Fekety R, Kim KH. Studies on the epidemiology of colitis due to Clostridium difficile in hamsters. J Infect Dis 1981;143:51-4.

${ }^{12}$ Mulligan ME, George WL, Rolfe RD, Finegold SM. Epidemiological aspects of Clostridium difficile-induced diarrhoea and colitis. Am J Clin Nutr 1980;33:2533-8.

${ }^{13} \mathrm{Kim} \mathrm{KH}$, Fekety R, Batts DH et al. Isolation of Clostridium difficile from the environment and contacts of patients with antibiotic-associated colitis. $J$ Infect Dis 1981;143:42-50.

${ }^{14}$ George WL, Sutter VL, Citron D, Finegold SM. Selective and으 differential medium for isolation of Clostridium difficile. J Clin Microbiol 1979;9:214-9.

${ }^{15}$ Sutter VL, Citron DM. Finegold SM. Wadworth anaerobic $\stackrel{\oplus}{+}$ bacteriology manual. St Louis. The CV Mosby Company, 1980.

${ }^{16}$ Houang ET, Tabaqchali S. Evaluation of Sensititre for sus-음 ceptibility testing of anaerobic bacteria. Current Chemotherapy $\overline{\bar{S}}$ 1978;I:475-7.

${ }^{17}$ Bartlett JG, Tedesco FJ, Shull S, Lowe B, Chang T. Symptomatic relapse after oral vancomycin therapy of antibiotic-associated pseudomembranous colitis. Gastroenterology 1980;78:431-4.

${ }^{18}$ Rogers TR, Petrou M, Lucas C et al. Spread of Clostridium difficile. among patients receiving non-absorbable antibiotics for gut $\vec{\overrightarrow{ }}$ decontamination. Br Med J 1981;283:408-9.

${ }^{19}$ Rolfe RD, Helebian S, Finegold SM. Bacterial interference $S$ between Clostridium difficile and normal faecal flora. J Infecto Dis 1981;143:470.

${ }^{20}$ Malamou-Ladas H, Tabaqchali S. Inhibition of Clostridium difficile by faecal streptococci. J Med Microbiol 1982 (in press).

"Rotimi VO, Duerden BI. The development of the bacterial flora in $\infty$ normal neonates. J Med Microbiol 1981;1:51-62.

${ }^{22}$ Viscidi R, Willey S, Bartlett JG. Isolation rates and toxigenic ${ }_{3}$ potential of Clostridium difficile isolates from various patient populations. Gastroenterology 1981;81:5-9.

${ }^{23}$ Donta ST, Stuppy MS. Neonatal antibiotic-associated colitis. $A m$ 今ึ J Dig Dis 1981;135:181-2.

${ }^{24}$ Hafiz S, McEntergart MG, Morton RS, Waitkins SA. Clostridium difficile in the urogenital tract of males and females. Lancet 1975 ;i:420-1.

Requests for reprints to: Dr S Tabaqchali, Department of Medical Microbiology, St Bartholomew's Hospital, West Smithfield, London EC1A 7BE, England. 